\title{
Editorial: Digital Transformation \& Digital Business Strategy in Electronic Commerce - The Role of Organizational Capabilities
}

\author{
Ayesha Nadeem ${ }^{1}$, Babak Abedin ${ }^{2}$, Narciso Cerpa $^{3}$ and Eng Chew ${ }^{4}$ \\ ${ }_{123}$ University of Technology Sydney, Faculty of Engineering and Information Technology, Sydney, Australia \\ Ayesha.Nadeem@student.uts.edu.au,Babak.Abedin@uts.edu.au \\ ${ }^{3}$ Universidad de Talca, Faculty of Engineering, Curicó, Chile \\ Editor-in-Chief \\ ncerpa@utalca.cl \\ ${ }^{4}$ University of Technology Sydney, Faculty of Design, Architecture and Building, Sydney, Australia \\ Eng.Chew@uts.edu.au \\ May 2017
}

\section{Overview}

Digital transformation is widely affecting various industries particularly healthcare, telecommunications, automotive, banking and manufacturing sectors. It enables innovation practices, improved designs, and new business models, and shapes how organizations create value on the Internet [9]. Companies can leverage robust customer relationships and increase cross selling opportunities through successful digital transformation [26], [28]. Digital transformation is not solely about acquiring and deploying the fit for purpose technologies; rather it is a significant approach in tackling managerial issues such as human resources, business efficiency, and business process redesign [17].

According to Hess [11], digital transformation has become a high priority on the leadership agenda of many organizations. Almost $70 \%$ of reported organizational transformation practices fail to meet organizations ambitions, the timeline for the transformation, or both [13], emphasizing the importance of the need for more research in this field. However, while the term digital transformation is increasingly being used in the electronic commerce research and practice, it has rarely been defined in the extant literature and professional articles. Thus, the first objective of this study is to review current understanding of this notion in the extant literature, and to explore what digital transformation entails.

Past studies in the information systems and electronic commerce literature have already reported the influence of various isolated technical factors such as technology use [10], data integration [4], and type of digital technologies [1], [4] as well as non-technical factors like digital leadership [5] and human resource management, and business process management [17] on digital transformation of organizations. The next objective of this editorial emphasizes the importance of digital strategy and organizational capabilities in successful digital transformation of organizations. Past research shows that business digital strategy [9], [15], digital capabilities [13], [24], [26] and implementation of right set of organizational capabilities [1], [24] are critical requirements for an effective and efficient enterprise transformation towards creating superior electronic-commerce customer-centric services in the digital era. Currently there is an inconsistent understanding of what constitutes organizational capabilities and a digital business strategy in a digital transformation process [1], [4], [6], [8], [9], [21], [22], [23], [24]. Thus, this study conducts a systematic literature review on a selected set of journals to explore what entails organizational capabilities and digital business strategy, and uses current empirical evidences for proposing a framework for future research on how these two factors may affect organizations' digital transformation.

\section{Methodology}

We have conducted a systematic literature review on selected leading Information Systems journals (see Table 1) for papers published from the year 2000 to 2017. We used combinations of three key terms for conducting the search on titles, abstracts, and keywords of each paper: Digital business strategy, Digital transformation, Business digitalization.

Table 1: Selected Journals for systematic literature review

\begin{tabular}{|l|l|}
\hline \multicolumn{2}{|l|}{ SELECTED JOURNALS } \\
\hline Journals & $\begin{array}{l}\text { MIS Quarterly, Journal of the association of Information Systems, Information System } \\
\text { Journal, Journal of Strategic Information Systems, Journal of Management Information } \\
\text { Systems, MISQ Executive, Sloan Management Review, Communications of the ACM, } \\
\text { Human computer -interaction, Behaviour and Information Technology, Information } \\
\text { Technology and People, Decision Support Systems, European Journal of Information } \\
\text { Systems, Information and Management, Information System Research, Journal of } \\
\text { Information Technology. }\end{array}$ \\
\hline
\end{tabular}


Following Bandara's guidelines [2], two main steps were conducted: (i) selecting the relevant sources to be searched [25], and (ii) defining the search strategy in terms of a time frame, search terms, and search fields [5], [16]. Figure 1 shows the process of relevant article selection.

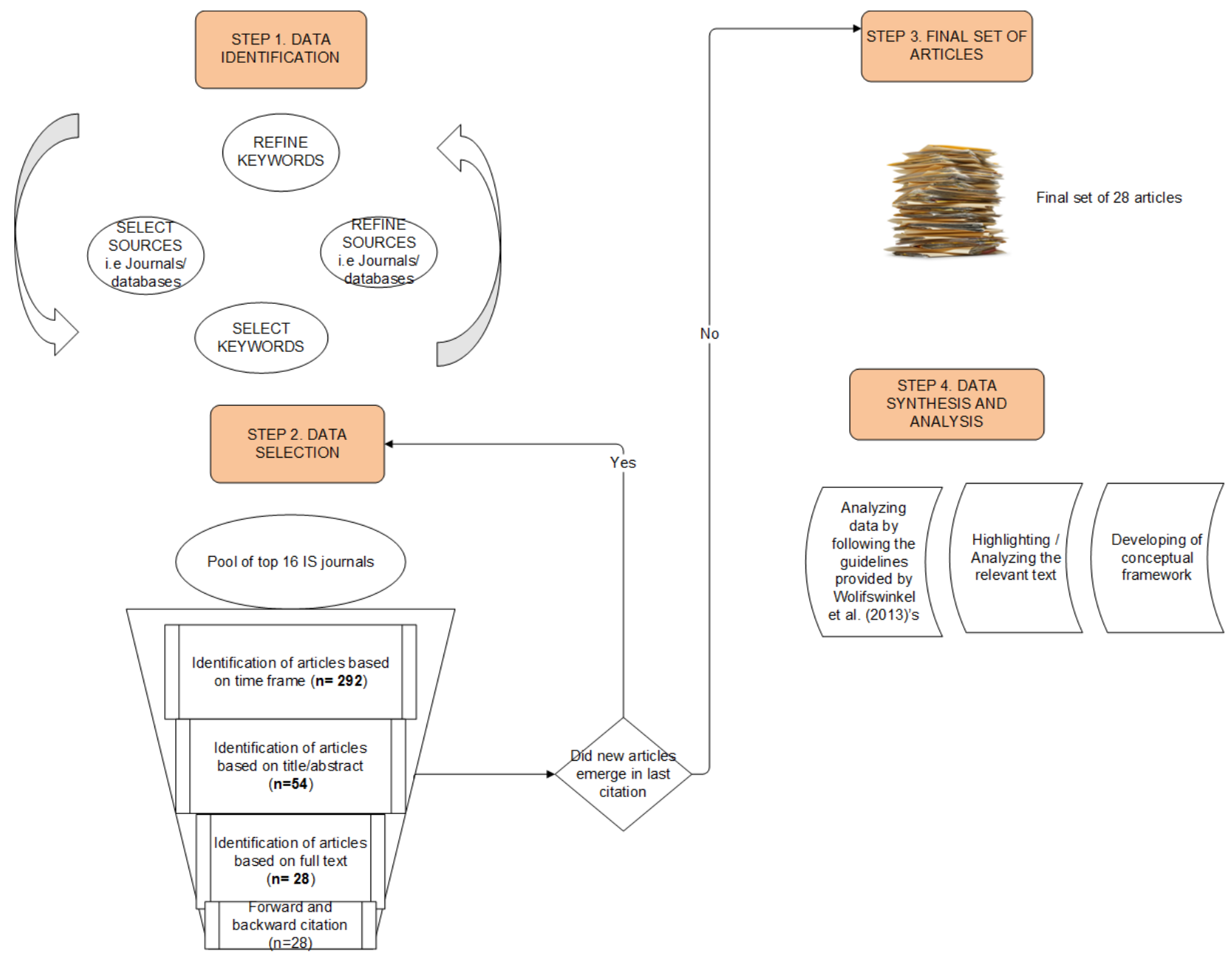

Figure 1: Process for selecting articles through systematic literature review

The first stage of our search resulted in 292 articles. After that, we checked the relevancy of the each paper to the research objectives in two stages: Firstly, we assessed this using each article's title, abstract, and keywords; this resulted in selection of 54 articles. Secondly, we examined the body of the selected articles, which led us to a final set of 28 articles. We then analysed these selected 28 articles thoroughly for their demographic information such as location, industry, and research methods, and then used Wolifswinkel's guidelines [27] for discovering the underlying dimensions of organizational capabilities, digital business strategy, and digital transformation.

Wolifswinkel's guidelines involve a systematic reading and application of codes to the final set of published articles, which would lead to identification of categories, sub-categories and core categories or themes. Figure 2 shows the qualitative process of analysing the systematic literature review final set of articles. We carried out the analysis of the articles in a stepwise mode. Initially, we read all the papers in detail, and highlighted sentences that seemed relevant to the research questions and research scope. The highlighted part from every article was termed as Excerpts [27]. We then read the excerpts repeatedly and noted in the logbook for future reference. During this process of excerption open coding takes place [27].

With open coding as the first step, we initiated the abstraction stage through reading all the papers and extracting dimensions [27]. We used the term dimensions instead of categories (as shown in figure 2) to reflect a characteristic or feature. Next, axial coding was conducted, in which dimensions were sub divided into sub-categories called attributes [27]. Attributes would be characteristics of each dimension. Each attribute of a dimension would be a unique feature and essential part of the dimension. Lastly, the process of comparative analysis took place [27], where linking and mapping of dimensions with attributes was carried out. This last stage of selective coding involved identification of core dimensions. The core dimensions represent the central phenomenon behind the study. It identifies the main idea the literature review represents. In this stage, we highlighted dimensions with a poor explanation or with no specific attributes representing, and we either eliminated them or merged them with another similar dimension. 


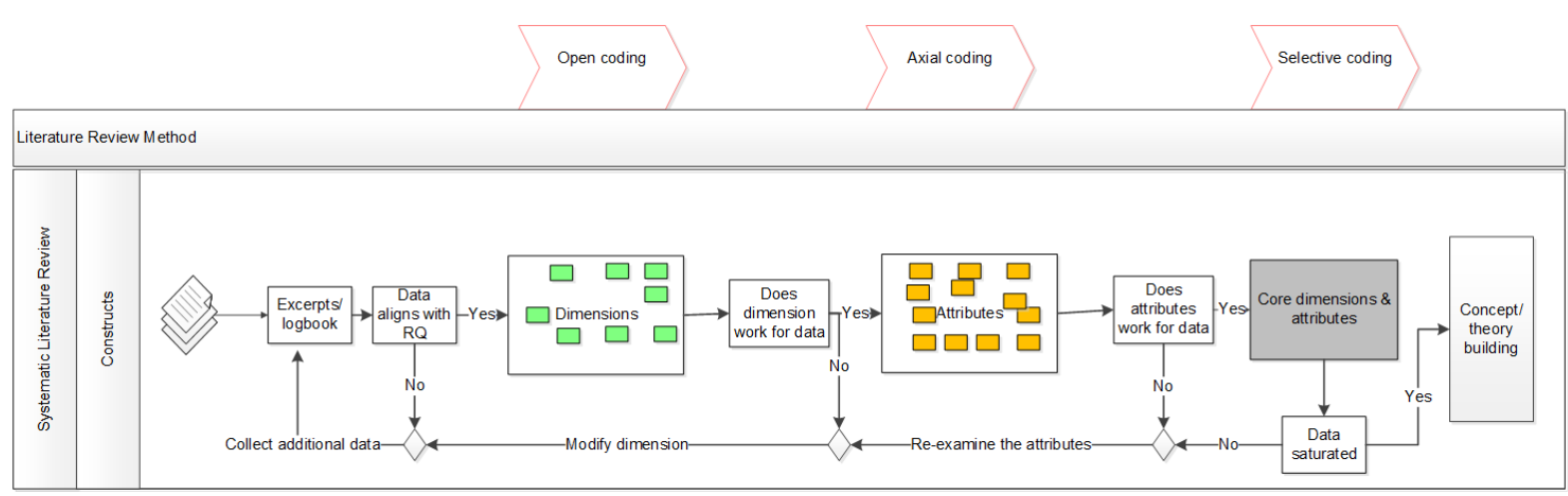

Figure 2: Process of analyses of systematic literature review articles

This above literature data coding process was carried out by going forward and backward between the articles as suggested by Wolifswinkel's. Once the data was exhausted or fully saturated only then the process of theory building starts [27]. Therefore, if any new dimensions or attributes emerged in this stage, we reviewed the data again starting from the excerptions process until the data was saturated.

\section{Outcomes of the Systematic Review}

As Figure 3 shows, the level of publication activity in this field started to increase from 2009 and then increased considerably in 2016. Furthermore, results also demonstrate that research on digital transformation has extensively been focusing on automotive industry, banking sector, telecommunications and healthcare, oil and gas and manufacturing sectors as shown below in Figure 4. Moreover, the literature review portrays that a large number of studies has concentrated on the US and European countries such as France, Germany, Switzerland, Denmark and UK, and in comparison, less work has been so far undertaken in Asia other regions like the Middle East, Latin America, and Africa.

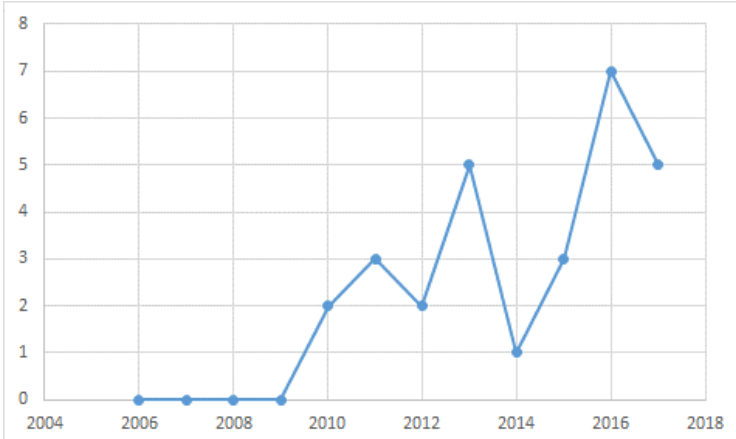

Figure 3: Publication trend of reviewed articles

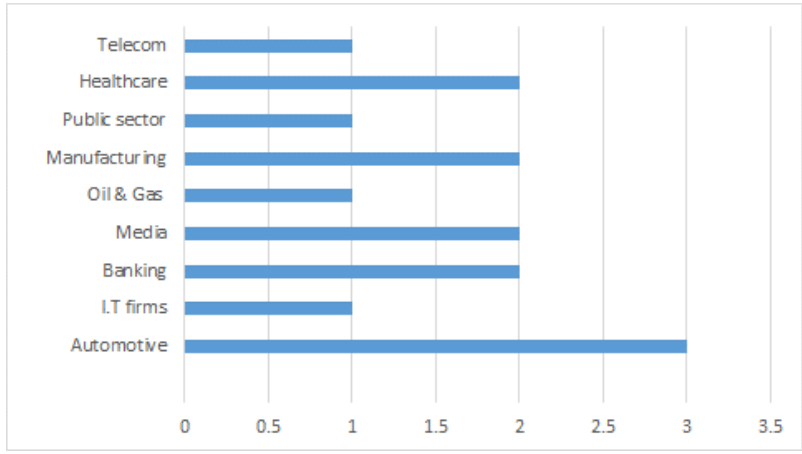

Figure 4: Selected papers by industry sector

In this study, we discuss the outcomes of the systematic review in two groups: firstly, we present what the notion of digital transformation entails and identify its underlying dimensions. We also discuss what digital business strategy and organizational capability may mean and what their underlying dimensions are based on past studies in the literature. Secondly, we aggregate the current empirical evidences to demonstrate how these three concepts may relate.

\section{The Underlying Dimensions}

Following Wolifswinkel's [27] guidelines and after completion of the coding process, the core dimensions and attributes for digital transformation, digital business strategy, and organizational capability were extracted and identified as shown below in Table 2. The final set of dimensions for digital transformation, digital business strategy and organizational capabilities were given a specific code as shown in the table below for proper identification and presentation. 
Table 2: Underlying Dimensions of digital transformation, digital business strategy, and organizational capability

\begin{tabular}{|c|c|c|c|}
\hline $\bar{E}$ & \# & Dimensions of DT & Description \\
\hline$\stackrel{\frac{1}{0}}{\frac{0}{0}}$ & DT1 & Use of technology & $\begin{array}{l}\text { Reflects a firm's capability to explore and exploit new } \\
\text { technologies [13] }\end{array}$ \\
\hline$\frac{5}{\frac{2}{2}}$ & DT2 & Value creation & $\begin{array}{l}\text { Reflects the influence of digital transformation on a firm's value } \\
\text { creation [13] }\end{array}$ \\
\hline$\frac{\text { F }}{\mathbb{2}}$ & DT3 & Structural changes & $\begin{array}{l}\text { Changes refer to the modifications in organizational structures, } \\
\text { processes \& skill sets [13], [24] }\end{array}$ \\
\hline$\overline{0}$ & DT4 & Financial aspects & $\begin{array}{l}\text { Relates to a firm's need for action and ability to finance in } \\
\text { response to digital transformation endeavour [13] }\end{array}$ \\
\hline & DT5 & Digital leadership & $\begin{array}{l}\text { New leadership roles and governance that facilitate rapid digital } \\
\text { transformation [12], [15], [24] }\end{array}$ \\
\hline & DT6 & $\begin{array}{l}\text { Agile \& scalable digital } \\
\text { operations }\end{array}$ & $\begin{array}{l}\text { Strategic initiatives to build operations that are scalable, flexible } \\
\text { and value capturing [24] }\end{array}$ \\
\hline & DT7 & Digitally enabled CEX & $\begin{array}{l}\text { Strategic initiatives for leveraging digital information for better } \\
\text { data optimization [24] }\end{array}$ \\
\hline & DT8 & Digital artefacts & $\begin{array}{l}\text { Strategic initiatives for continuously navigating the digital } \\
\text { landscape and technology scanning and implementation [24] }\end{array}$ \\
\hline & DT9 & $\begin{array}{l}\text { Executing business strategy } \\
\text { digitally }\end{array}$ & $\begin{array}{l}\text { Building business strategy digitally around the enterprise core } \\
\text { distinctive competencies [9], [15] }\end{array}$ \\
\hline & $\begin{array}{l}\text { DT1 } \\
0\end{array}$ & $\begin{array}{l}\text { External collaboration of } \\
\text { ecosystem of digital platform }\end{array}$ & $\begin{array}{l}\text { Leveraging ecosystem of partners for complementary } \\
\text { competencies involving value proposition and revenue sharing } \\
\text { [9] }\end{array}$ \\
\hline & $\begin{array}{l}\text { DT1 } \\
1\end{array}$ & platform & $\begin{array}{l}\text { Intensive interactive digital connectivity to the outside and inside } \\
\text { enterprise [9] }\end{array}$ \\
\hline & $\begin{array}{l}\text { DT1 } \\
2\end{array}$ & $\begin{array}{l}\text { Flexible } \\
\text { workplace }\end{array}$ & $\begin{array}{l}\text { Providing a flexible and attractive workplace for born digital } \\
\text { employees [9] }\end{array}$ \\
\hline क & \# & Dimensions of DBS & Description \\
\hline 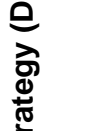 & DT1 & $\begin{array}{l}\text { External collaboration of } \\
\text { ecosystem of digital platform }\end{array}$ & $\begin{array}{l}\text { Leveraging ecosystem of partners for complementary } \\
\text { competencies involving value proposition and revenue sharing } \\
\text { [9] }\end{array}$ \\
\hline के & DT2 & IT infrastructure & $\begin{array}{l}\text { A fusion of IT with business using IT application systems [4], } \\
{[13],[24]}\end{array}$ \\
\hline 兽 & DT3 & Cross-functional integration & $\begin{array}{l}\text { Reconfiguration of IT and business resources across multiple } \\
\text { organizational processes [24] }\end{array}$ \\
\hline : & DT4 & $\begin{array}{l}\text { Organizational structural } \\
\text { changes }\end{array}$ & Rethinking the role of corporate IT and $\mathrm{CIO}$ [9] \\
\hline & DT5 & Use of technology & $\begin{array}{l}\text { Extend to which a firm engages in any category of IT investment } \\
\text { [21] }\end{array}$ \\
\hline & DT6 & New dynamic capabilities & $\begin{array}{l}\text { Building advance capabilities in response to environmental } \\
\text { turbulence [9] }\end{array}$ \\
\hline & \# & Dimensions of OC & Description \\
\hline 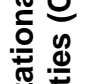 & OC1 & Digital leadership & $\begin{array}{l}\text { Developing and acquiring new competencies and ambidextrous } \\
\text { skill [24] }\end{array}$ \\
\hline ô & OC2 & Agile \& scalable operations & $\begin{array}{l}\text { Building robust and flexible operations to overcome the } \\
\text { constraints of legacy systems [9], [24] }\end{array}$ \\
\hline
\end{tabular}




\begin{tabular}{|c|c|c|}
\hline \multicolumn{3}{|c|}{ Table 2: continuation } \\
\hline OC3 & Digitally enabled CEX & $\begin{array}{l}\text { Deeper analysis of value proposition and seamless integration } \\
\text { of functional silos across the enterprise [24] }\end{array}$ \\
\hline OC4 & Digital artefacts & $\begin{array}{l}\text { Developing continuously new digital processes, infrastructures, } \\
\text { services and products handling large amount of data [24], [26] }\end{array}$ \\
\hline OC5 & $\begin{array}{l}\text { Flexible \& scalable digital } \\
\text { platforms }\end{array}$ & Platforms that are tailored to their particular need [14] \\
\hline OC6 & $\begin{array}{l}\text { Internal \& managerial } \\
\text { capabilities }\end{array}$ & Defining roles and structures having diverse skill set [14] \\
\hline OC7 & $\begin{array}{l}\text { External collaboration of } \\
\text { ecosystem of digital } \\
\text { platforms }\end{array}$ & $\begin{array}{l}\text { Developing collaboration with external partners to co-create } \\
\text { value [14] }\end{array}$ \\
\hline OC8 & Dynamic capabilities & $\begin{array}{l}\text { Powerful capabilities to cope up with turbulence [4], [9], [16], } \\
\text { [23], [26] }\end{array}$ \\
\hline OC9 & Plug \& play capabilities & $\begin{array}{l}\text { Assessing unique drivers in digital settings for modularizing the } \\
\text { business processes [4] }\end{array}$ \\
\hline OC10 & Operational capabilities & $\begin{array}{l}\text { Developing capabilities for sudden changes in market demands } \\
\text { [9], [21] }\end{array}$ \\
\hline
\end{tabular}

Table 2 delineates the dimensions the each of the three concepts along with their description. We identified twelve dimensions of digital transformation. Similarly, we identified six dimensions of digital business strategy and ten dimensions of organizational capabilities. This was to address the gap in the literature in terms of providing a synthesis of the literature for identification of underlying dimensions for each of the three factors. The above table summarizes the findings from the extant literature and gives a guideline to the upcoming researchers and industry professionals.

Next, we assessed how the dimensions in Table 2 may overlap. It signifies the common dimensions that have overlapped, and highlights how they are related. This graphical representation depicts that the common dimension shared by digital transformation, digital business strategy and organizational capabilities is collaborative ecosystem of digital platform. And the common dimension shared by digital transformation and digital business strategy are named as use of technology and structural changes whereas the common dimensions shared by digital transformation and organizational capabilities are names as digital leadership, agile and scalable operations, digitally enabled customer service unit (CSU) \& digital artefacts. Moreover, the common dimension shared by digital business strategy and organizational capabilities is dynamic capabilities as shown in Figure 5.

Previous literature has not presented the inter-relationship of the digital transformation, digital business strategy, and organizational capabilities. Thus, Figure 5 is what our review resulted in proposing a relationship between digital business strategy, and digital transformation, are organizational capabilities. It suggests that digital transformation is the digital business strategy in action. If deployed successfully, digital business strategy is only the blueprint that can lead to digital transformation. This framework shown in figure 5 signifies and highlights the organizational capabilities that an organization need to acquire for deploying digital transformation and digital business strategy. Although digital transformation, digital business strategy, and organizational capabilities are termed as three different concepts, they actually have inter-relationships as shown in figure 5. The external collaboration of ecosystem of digital platforms shared by all the three concepts highlights that developing the collaboration with external partners is significant in today's digital world for co-creating value and better organizational performance. The firm's digital leadership, agile and scalable operations, digital enabled customer service unit (CSU) and digital artefacts, can manifest organizational capabilities required for pursuing the digital transformation to align with the changing external environments. Digital leadership describes that organizations should acquire more recent and updated digital skills and competencies whilst introducing new leadership roles to match the electronic commerce's changing external environments. Likewise, building flexible and vigorous operations would assist in overcoming the previously embedded legacy systems further assisting the organization in deploying the digital transformation to make the firm's electronic commerce remaining relevant. Furthermore, digitally enabled CSU is another important element in response to changing customer, as it assists with analysing customers value proposition in the electronic commerce context, which would be achieved by developing and implementing the digital processes and infrastructures that would be beneficial in handling large amount of data. Digital capabilities facilitated by digital artefacts would therefore enable the firm to create or adapt new products / services for its electronic commerce to fulfil the desired digitally enabled CSU to fit with the changing customer needs. 


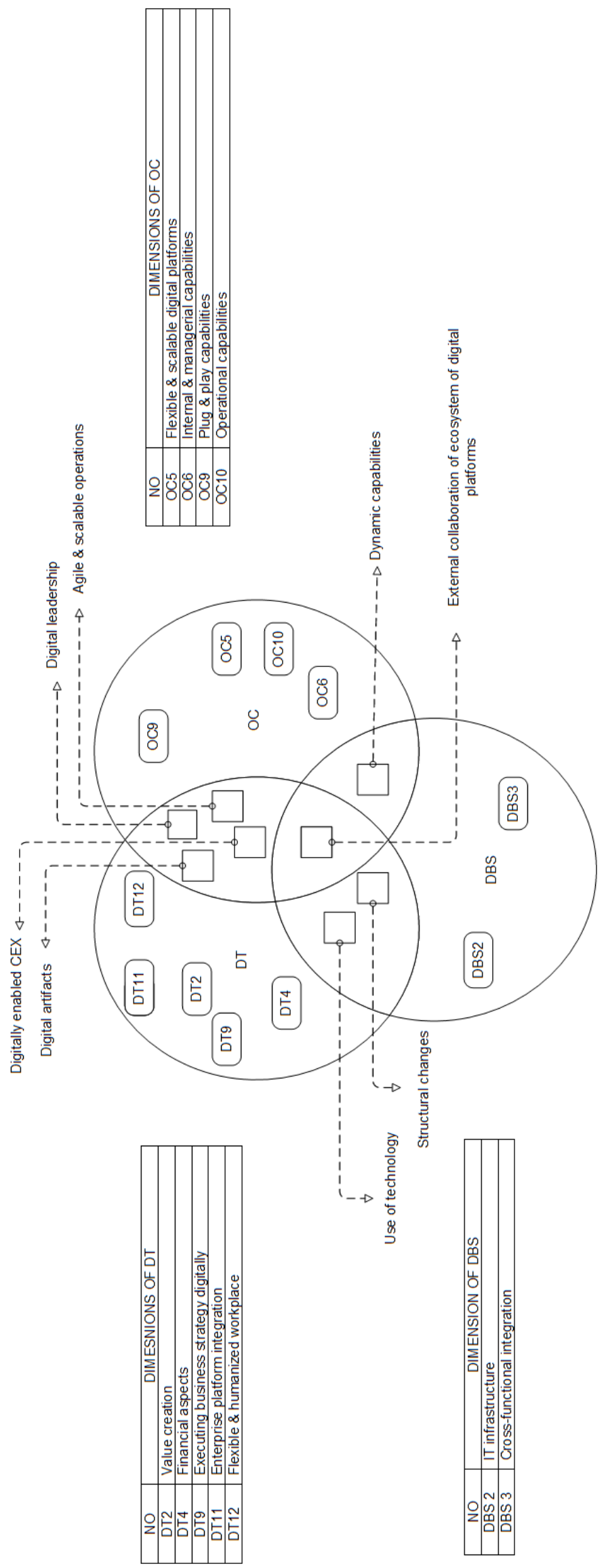

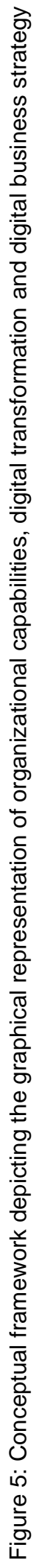


It is noted that digital business strategy requires the development of new organizational capabilities that are developed and reconfigured on a continuous basis [4], [21], [22]. Additionally, in order to seize the benefits of digital transformation, more efforts need to be focused on the development of a competitive digital business strategy [7] - i.e. specifically digital strategy initiatives need to be defined for the execution of the digital transformation [12]. In addition, past literature also highlights that market-alignment drivers of organizational capabilities would help identify the organization's drivers for digital transformation in electronic-commerce [12], [14], which in turn would lead to better business performance [19]. Figure 6 below represents the relationship between organizational capabilities, digital transformation and digital business strategy.

Sia, Soh \& Weill 2016, Bharadwaj et al.
2013 , Setia, Venkatesh \& Joglekar 2013 Ross, Sebastian \& Beath 2017

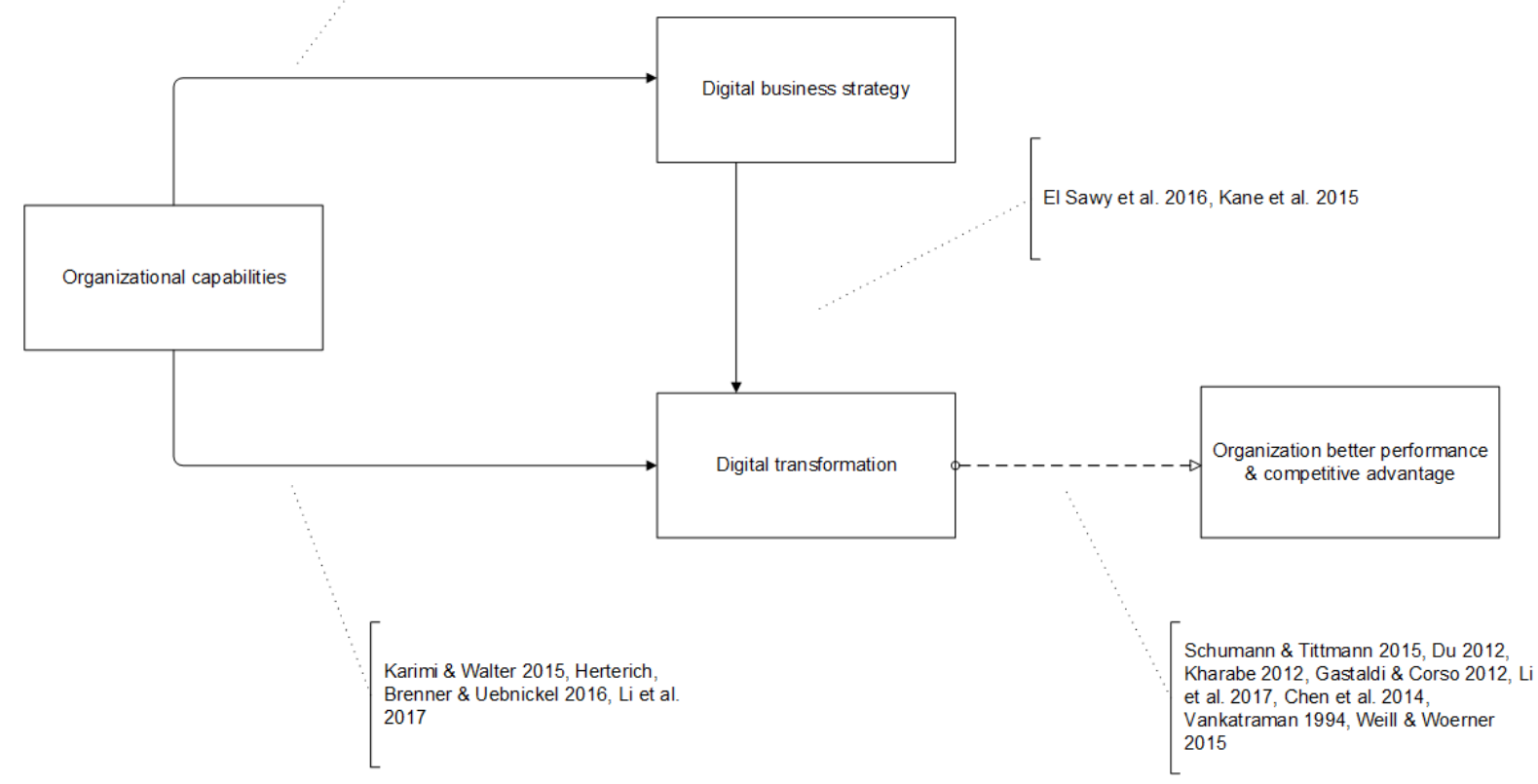

Figure 6: Relationship between organizational capabilities, digital transformation \& digital business strategy

\section{Conclusion}

This study explores the inter-relationship between the organizational capabilities, digital transformation and digital business strategy, which further led to the emergence of the conceptual framework. It explains and demonstrates how the requisite set of organizational capabilities and unique dimensions of digital business strategy would drive an organization towards digital transformation. The digital transformation framework described by Figure 5 together with the causal interrelationship between organizational capabilities and digital transformation (moderated by digital business strategy) as shown in Figure 6 would represent a new important body of knowledge on the fundamental managerial practices for digital transformation towards a successful electronic commerce.

The analysis resulted in distinctive dimensions of digital transformation, digital business strategy, and organizational capabilities. This study provides a broader and substantial theoretical contribution on digital transformation literature and it enriches the literature by providing a framework of the inter-relationship of the organizational capabilities, digital transformation and digital business strategy. This research also represents the unique set of dimensions entailed by digital transformation, digital business strategy and organizational capabilities.

The findings would assist organizations' CEOs and CIOs (C-suite management) who are looking for an effective framework depicting the inter-relationship between the digital transformation, organizational capabilities and digital business strategy. Companies usually hire consulting firms to assist them in developing and deploying fit-for-purpose organizational capabilities for pursuing digital business strategy that further leads to digital transformation. However, they would often end up investing a huge amount in implementing digital technologies instead and would still be unable to achieve effective digital transformation throughout the organization. Therefore, this study would guide them in determining and deploying the right organizational capabilities for their organization for digital transformation leading to better performance.

Another stakeholder of this study would be the IS researchers, who are in the search for a step forward in developing and implementing digital business strategy and digital transformation. IS researchers have previously published many 
articles on this topic in various journals and therefore have shown a growing concern for an awareness of this field. The IS researchers would gain an improved understanding of the challenges faced in digital transformation.

\section{References}

[1] B. Abedin and A. Babar. (2017, August) Institutional vs. non-institutional use of social media during emergency response: A case of twitter in 2014 Australian bush fire. Information Systems Frontiers. [Online]. Available: https://link.springer.com/article/10.1007/s10796-017-9789-4

[2] W. Bandara, S. Miskon and E. Fielt, A systematic tool supported method for conducting literature reviews in information systems, presented at the 19th European Conference on Information Systems, Helsinki, Finland, June 9-11, 2011.

[3] K. Berger, J. Klier, M. Klier, and F. Probst, A review of information systems research on online social networks, Communications of the association for Information Systems, vol. 35, no. 8, pp. 145-172, 2014

[4] A. Bharadwaj, O. A. El Sawy, P. A. Pavlou, and N. Venkatraman, Digital business strategy: Toward a next generation of insights, MIS Quarterly, vol. 37, no. 2, pp. 471-482, 2013.

[5] H. M. Cooper, Organizing knowledge syntheses: A taxonomy of literature reviews, Knowledge in society, vol. 1, no. 1 , pp. 104-126, 1988 .

[6] J.T Du, Information use and information sharing in marketing: A diary study, Proceeding of the association for Information Science and Technology, vol. 49, no, 1, pp. 1-4, 2012.

[7] O.A El Sawy, P. Kraemmergaard, H. Amsinck, and A. L. Vinther, How LEGO built the foundations and enterprise capabilities for digital leadership, MIS Quarterly Executive, vol. 15, no. 2, pp. 141-166, 2016.

[8] L. Gastaldi and M. Corso, Smart healthcare digitalization: Using ICT to effectively balance exploration and exploitation within hospitals, International Journal of Engineering Business Management, vol. 4, 2012.

[9] G. Gudergan and P.Mugge, The gap between practice and theory of digital transformation, in Proceeding Hawaii International Conference of System Science, Hawaii, 2017, pp. 1-15.

[10] A.M. Hansen, P. Kraemmergaard and L. Mathiassen, Rapid adaption in digital trasnsformation: A participatory process for engaging IS and business leaders, MIS Quarterly Executive, vol. 10, no. 4, 2011.

[11] T. Hess, C. Matt, F. Wiesbock, and A. Benlian, Options for formulating a digital transformation strategy, MIS Quarterly Executive, vol. 15, no. 2, pp. 103-119, 2016.

[12] H. Jafarzadeh, H. Aurum, J. D'Ambra, B. Abedin, and B. Assemi, Search engine advertising adoption and utilization: An empirical investigation of inflectional factors, Organizational Computing and Electronic Commerce, vol. 25, no. 4, pp. 402-427, 2015.

[13] G.C. Kane, D. Palmer, A. N. Phillips, D. Kiron, and N. Buckley, Aligning the organization for its digital future, MIT Sloan Management Review, vol. 57, no. 4, 2016

[14] J. Karami and Z. Walter, The role of dynamic capabilities in responding to digital disruption: A factor based study of the newspaper industry, Journal of Management Information System, vol. 32, no. 1, pp. 39- 81, 2015.

[15] M.Lansiti and K. Lakhani, Digital Ubiquity-How connections, sensors and data are revolutionizing business, Harvard Business Review, 2014

[16] Y. Levy and T.J. Ellis, A systems approach to conduct an effective literature review in support of information systems research, Information Science: International Journal of an Emerging Trans-Discipline, vol. 9, pp. 181212, 2006.

[17] L. Li, F. Su, W. Zhang and J. Ye Mao, Digital transformation by SME entrepreneurs: A capability perspective, Information System Journal, June 2017.

[18] S. Mathrani, A. Matharni and V. Veihland, Using enterprise systems to realize digital business strategies, Journal of Enterprise Information Management, vol. 42, no, 5, pp. 9-17, 2012.

[19] S. Mithas, A. Tafti and W. Mitchell, How a firm's competitive environment and digital strategic posture influence Digital Business Strategy, MIS Quarterly, vol. 37, no. 2, pp. 511- 536, 2013.

[20] J.W. Ross, I.M Sebastian and C.M Beath, How to develop a great digital strategy, MIT Sloan Management Review, vol. 58, no. 2, 2017.

[21] P. Setia, V. Venkatesh and S. Joglekar, Leveraging digital technologies: How information quality leads to localized capabilities and customer service performance, MIS Quarterly, vol. 37, no. 2, pp. 565-590, 2013.

[22] S.K. Sia, C. Soh and P. Weill, How DBS bank pursued a Digital Business Strategy, MIS Quarterly Executive, vol. 15, no. 2, pp. 105-121, 2016.

[23] C.A. Schumann and C. Tittmann, Digital transformation in context of knowledge management, in Proceedings European Conference on Knowledge Management, Germany, 2015.

[24] F. Svahn, L. Mathiassen and R. Lindgren, Embracing digital innovation in incumbent firms: How Volvo cars managed competing concerns, MIS Quarterly, vol. 41, no. 1, pp. 239-253, 2017.

[25] J. Webster and R.T Watson, Analyzing the past to prepare for the future: Writing a literature review, MIS Quarterly, vol. 26, no. 2, pp. 13-23, 2002.

[26] P.D Weill and S. Woerner, Thriving in an increasingly digital ecosystem, MIT Sloan Management Review, vol. 57, no. 3, 2015.

[27] J.F Wolfswinkel, E. Furtmueller and C. P. M. Wilderom, Using grounded theory as a method for rigorously reviewing literature, European Journal of Information Systems, vol. 22, no. 1, pp. 45-55, 2013.

[28] G. Westerman and D. Bonnet, Revamping your business through digital transformation, MIT Sloan Management Review, vol. 56, no. 3, pp. 10-13, 2015 